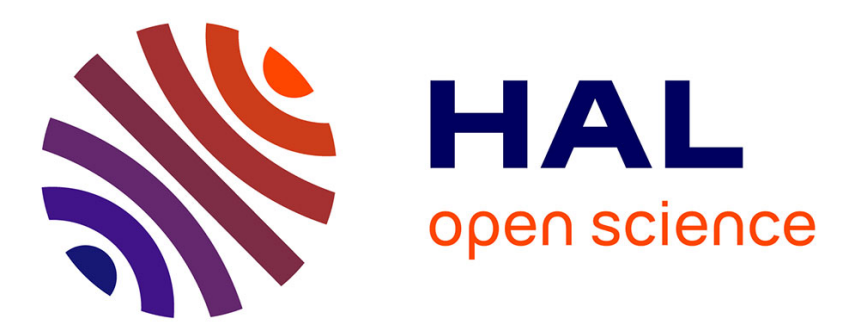

\title{
Damien Baldin, Histoire des animaux domestiques, XIXe-XXe siècle, Paris, Seuil, 2014 \\ Arnaud Exbalin
}

\section{To cite this version:}

Arnaud Exbalin. Damien Baldin, Histoire des animaux domestiques, XIXe-XXe siècle, Paris, Seuil, 2014. Histoire urbaine, 2016. hal-01471825

\section{HAL Id: hal-01471825 \\ https://hal.parisnanterre.fr/hal-01471825}

Submitted on 4 Jun 2019

HAL is a multi-disciplinary open access archive for the deposit and dissemination of scientific research documents, whether they are published or not. The documents may come from teaching and research institutions in France or abroad, or from public or private research centers.
L'archive ouverte pluridisciplinaire HAL, est destinée au dépôt et à la diffusion de documents scientifiques de niveau recherche, publiés ou non, émanant des établissements d'enseignement et de recherche français ou étrangers, des laboratoires publics ou privés. 
Damien Baldin, Histoire des animaux domestiques, $X I X^{e}-X X^{e}$ siècle, Paris, Seuil, 2014

Arnaud Exbalin/ Université Paris Ouest-Mondes Américains

L'ouvrage que Damien Baldin a fait paraître aux éditions du Seuil en 2014 témoigne de la vigueur des études en sciences sociales consacrées aux relations des hommes aux animaux domestiques, dans le prolongement des travaux pionniers engagés par l'anthropologie. Dès l'introduction, l'auteur nous met en garde : son propos ne relève pas du très en vogue "tournant animaliste " qui s'attache à faire l'histoire des animaux du point de vue animal mais traite " des formes sociales et culturelles et des discours pas lesquels les hommes les domestiquent ». Après les travaux décisifs de Jean-Pierre Digard, la tâche était ambitieuse d'autant que Damien Baldin intègre dans son livre tous les animaux domestiques (chiens, chats, veaux, oiseaux, volaille, lapins, chevaux jusqu'aux vers à soie) aussi bien dans le monde des campagnes que dans celui des villes, et ce, sur un long XIX ${ }^{e}$ siècle, du siècle des Lumières finissant jusqu'au milieu du $X X^{e}$ siècle. Cette périodisation se justifie triplement: d'une part, parce que la démographie animale y atteint un maximum; d'autre part, parce que cette période est la matrice du perfectionnement scientifique du dressage, de la médecine vétérinaire et de la zootechnie; enfin, parce que c'est le moment où se développe les premiers mouvements de protection animale.

Le texte, porté par une écriture limpide, s'appuie sur une documentation foisonnante : imprimés d'agronomes et de vétérinaires, livres de dressage, témoignages de médecins, archives policières mais aussi extraits de romans. La mise au point historiographique est impeccable même si certains travaux (ceux de Nathalie Blanc ou le magnifique Paysage animal de Xavier de Planhol paru en 2004 chez Fayard) auraient pu être mentionnés dans une bibliographie certes déjà très fournie. L'ensemble est fermement structuré autour de quatre épais chapitres.

Le premier chapitre ("Vivre en familiarité ») porte sur les rapports de familiarité qui lient hommes et animaux domestiques dans la société française $d u X I X$ siècle. Le recours à de très nombreux témoignages - parfois à la limite de l'impressionnisme - puisés entre autres aux sources littéraires (Rousseau, Zola, Sand, Hugo) et à la peinture permet de plonger dans l'intimité de ces relations. Cette familiarité prend toute sa consistance lorsque l'auteur évoque les avis de recherche de chiens perdus via des billets placardés dans les rues de la capitale dès la fin du XVIII ${ }^{\mathrm{e}}$ siècle ou encore l'aménagement d'un cimetière pour chiens sur une île de la Seine à Asnières à la fin du XIX ${ }^{\mathrm{e}}$ siècle.

Le deuxième chapitre ("dresser et améliorer ») est consacré à ce que la science fait aux animaux domestiques, depuis l'Histoire naturelle de Buffon jusqu'aux travaux de psychologie animale de G. Bohn, l'amélioration des races étant le fil rouge du chapitre. L'auteur rappelle que la maîtrise des races équines fut, de manière très précoce, encouragée par l'État royal qui créa sous Louis XIV les premiers haras nationaux pour des raisons militaires. Au-delà, à une échelle individuelle, la possession d'un animal de race fut un critère de distinction sociale, un faire-valoir individuel clairement observable dans la relation noblesse/cheval.

Le troisième chapitre ("Protéger ») vise à éclairer, à partir des travaux pionniers de Maurice Agulhon, des enjeux complexes que recouvrent la législation (loi Grammont de 1850) et les associations (SPA en 1848) de protection des animaux domestiques. Certes, la législation atteste d'une nouvelle conception de l'animal - de plus en plus considéré comme un être sensible - mais elle relève d'abord de motivations économiques car battre un animal est improductif. Plus profondément, le succès des associations, dont l'auteur fait une appréciable analyse sociologique, illustre la prégnance d'un discours moralisateur des élites sur la brutalité des mœurs des classes populaires. Ce discours irrigue jusqu'aux manuels scolaires de la III $^{\mathrm{e}}$ République qui stigmatisent les comportements rustres des classes laborieuses. Le glissement vers des motivations proprement 
" animalitaires » (Digard) ne s'opère que tardivement, à l'orée du XX ${ }^{\mathrm{e}}$ siècle. Signes de cette nouvelle sensibilité, la condamnation de la vivisection - déjà présente chez Louis-Sébastien Mercier - ou encore le recul puis l'abandon de la traction canine, une pratique alors fort commune dans les villes jusqu'aux années 1860.

Le dernier chapitre ("Enfermer, éliminer ») est selon nous la partie la plus novatrice de l'ouvrage. Elle se fonde sur des recherches en archive notamment à la préfecture de police de Paris: Damien Baldin en a fait son sujet de thèse, sur la police des chiens, sous la direction de Stéphane AudoinRouzeau. L'auteur s'intéresse ici à la gestion administrative et policière des animaux errants et des bêtes de boucherie. L'omniprésence animale en ville génère en effet son lot de nuisances au moment où prospèrent les politiques hygiénistes: embarras, morsures et maladies dont la rage, bruits et odeurs d'excréments ou de cadavres en putréfaction qui génèrent le risque d'une contamination généralisée et la peur d'un ensauvagement de la société. L'horreur de la vue du sang se traduit d'abord par des mutations spatiales comme les abattoirs ou les centres d'équarrissage alors transférés vers la périphérie de la capitale. La gestion des bêtes errantes s'illustre quant à elle par des règlements (dès 1725 selon l'auteur) qui forcent les propriétaires à utiliser des instruments visant à assujettir davantage leurs animaux de compagnie en particulier les chiens: laisse, collier, muselière. II est probable - nous l'ajoutons - que cette règlementation soit bien plus ancienne, dès l'époque médiévale, comme l'ont suggéré récemment plusieurs participants au colloque organisé par la SFHU (Animaux dans la ville) en janvier 2015. C'est dans le cadre de cette chasse à l'errance animale en ville que sont créées les premières fourrières, d'abord simples enclos pour les bêtes recueillies sur la voie publique, avant de devenir des dépôts pour chiens relevant de la préfecture de Paris. Chaque soir, le gardien est chargé d'abattre les chiens non réclamés - de fait $95 \%$ des chiens déposés - ce qui explique dans le même temps le succès des refuges. Les techniques d'élimination utilisées dans les fourrières font l'objet de passionnants développements : pendaisons, coups de massue, noyade et le gaz qui a le pouvoir de rendre " la mort invisible ». Dans les abattoirs, la même logique de mort douce a cours, depuis la saignée au couteau sous l'Ancien Régime au pistolet à tige percutante appelé par euphémisme " pistolet humanitaire ». Mais l'auteur se garde bien de tomber dans le travers d'une lecture simplement hygiéniste des procédés d'enfermement et d'élimination mis en œuvre : ces animaux sont en effet au contact de certaines catégories sociales (chiffonniers, éboueurs, équarisseurs, vagabonds) et forment un "bas-fond animalisé » qui menace la bonne société citadine. Dès lors les dispositifs qui sont exercés sur les animaux participent d'une ingénierie sociale destinée à « dresser » les classes laborieuses et misérables. 